\title{
Enhancing Blue Emission in Ce Doped Silicon Oxynitrides Based Electroluminescent Devices
}

\author{
F. Ehré, $\odot{ }^{1,2, z}$ C. Dufour, ${ }^{2}$ O. Blázquez ${ }^{3}$ B. Garrido, ${ }^{3}$ W. M. Jadwisienczak, ${ }^{4}$ D. C. Ingram, ${ }^{5}$ \\ J. Cardin, ${ }^{2}$ F. Gourbilleau, ${ }^{2}$ X. Portier, ${ }^{2}$ C. Guillaume, ${ }^{2}$ Baodan Liu, ${ }^{6}$ and C. Labbé ${ }^{2}$ \\ ${ }^{1}$ LPV, Physics and Material Science Research Unit, University of Luxembourg, L-4422 Belvaux, Luxembourg \\ ${ }^{2}$ CIMAP Normandie University, ENSICAEN, UNICAEN, CEA, CNRS, 14050 Caen, France \\ ${ }^{3}$ MIND-IN2UB, Departament d'Enginyeria Electrònica i Biomèdica, Universitat de Barcelona, E 08028 Barcelona, \\ Spain \\ ${ }^{4}$ School of Electrical Engineering and Computer Science, Ohio University, Athens, Ohio 45701, USA \\ ${ }^{5}$ Department of Physics and Astronomy, Ohio University, Athens, Ohio 45701, USA \\ ${ }^{6}$ Shenyang National Laboratory for Materials Science (SYNL), Institute of Metal Research (IMR), Chinese Academy of \\ Sciences (CAS)
}

\begin{abstract}
Ce-doped $\mathrm{SiO}_{\mathrm{x}} \mathrm{N}_{\mathrm{y}}$ and $\mathrm{SiAlON}$ matrices are promising materials for blue LED applications. The uniqueness of this approach stems from the fact that $\mathrm{SiO}_{\mathrm{x}} \mathrm{N}_{\mathrm{y}}$, as a host, combines specific properties of individual $\mathrm{SiO}_{\mathrm{x}}$ and $\mathrm{SiN}_{\mathrm{y}}$ matrices like solubility, efficient emission, $5 \mathrm{eV}$ gap, with a broad excitation range from $400 \mathrm{~nm}$ to $500 \mathrm{~nm}$ of $\mathrm{Ce}^{3+}$ ions due to the $4 f-5 d$ transitions. Furthermore, the co-doping with aluminum enhances the $\mathrm{Ce}^{3+}$ emission. In this work, we fabricated electroluminescent devices using $\mathrm{SiO}_{\mathrm{x}} \mathrm{N}_{\mathrm{y}}: \mathrm{Ce}^{3+}$ and SiAlON:Ce ${ }^{3+}$ as active layers and investigated the resulting emission under optical and electrical excitations as a function of nitrogen, cerium and aluminum concentrations. $I-V$ measurements were conducted to determine the $\mathrm{SiO}_{\mathrm{x}} \mathrm{N}_{\mathrm{y}}: \mathrm{Ce}^{3+}$ layer electrical parameters. Charge transport through the devices obeys the Poole-Frenkel conduction mechanism. It was demonstrated that by optimizing the $\mathrm{SiO}_{\mathrm{x}} \mathrm{N}_{\mathrm{y}}: \mathrm{Ce}^{3+}$ growth parameters, an improvement of electroluminescence yield can be achieved with a maximum intensity obtained for devices with cerium content of 4 at.\%.
\end{abstract}

Rare earth (RE) doped silicon based materials have been extensively investigated in the past few years. Various hosts were doped with $\mathrm{Er}^{3+}$ ions that emit at $1.5 \mu \mathrm{m}$ corresponding to the maximum transparency of silica used in telecommunications. ${ }^{1}$ For the $\mathrm{Ce}^{3+}$ ion, up to date, only a few studies have been reported on its electroluminescence (EL). ${ }^{2}$ Among the silicon-based matrices, silica $\left(\mathrm{SiO}_{2}\right)$ and silicon nitride $\left(\mathrm{Si}_{3} \mathrm{~N}_{4}\right)$ have been explored; however, each of them present certain advantages and drawbacks. In the case of silica matrices, achievement of strong $\mathrm{RE}^{3+}$ ions emission is limited by a low excitation cross section, ${ }^{3}$ a low RE solubility as well as RE clusters formation. ${ }^{4,5}$ However, the main drawback limiting $\mathrm{SiO}_{2}$ : $\mathrm{RE}^{3+}$ light emitting applications comes from the large bandgap of the matrix $(\sim 9 \mathrm{eV})$ resulting in low electrical conductivity. On the other hand, $\mathrm{Si}_{3} \mathrm{~N}_{4}$ with a smaller energy bandgap $(4 \mathrm{eV})$ and reduced tendency of the RE to form clusters, seems to be more suitable for RE doping. ${ }^{6-8}$ However, despite these advantages, the emission efficiency from $\mathrm{RE}^{3+}$ ions in a nitride matrix is much lower than in silica matrix. ${ }^{9}$ To capitalize on the RE doping advantages offered by both oxide and nitride silicon matrices, a Ce-doped $\mathrm{SiO}_{\mathrm{x}} \mathrm{N}_{\mathrm{y}}$ matrix has been explored by Ramirez et al. ${ }^{10}$ It was reported that the maximum EL peak from $\mathrm{Ce}^{3+}$ ion shifted from $400 \mathrm{~nm}$ to $476 \mathrm{~nm}$ as function of the nitrogen concentration (i.e. the nephelauxetic effect). ${ }^{10,11}$ Koao et al. showed that aluminum co-doping Ce-doped $\mathrm{SiO}_{2}$ glasses lead to an enhancement of photoluminescence emission. ${ }^{12}$ In this work, Ce-doped $\mathrm{Si}(\mathrm{Al}) \mathrm{O}_{\mathrm{x}} \mathrm{N}_{\mathrm{y}}$ layers with a typical thickness of $50 \mathrm{~nm}$ were grown by sputter deposition. Photoluminescence (PL) from the $\mathrm{SiO}_{\mathrm{x}} \mathrm{N}_{\mathrm{y}}: \mathrm{Ce}^{3+}$ layers and EL from this active layer were examined for device performance as a function of growth parameters and material composition.

\section{Experimental}

Active layer preparation.-The devices were fabricated in a few step processes. First, the Ce-doped $\mathrm{SiO}_{\mathrm{x}} \mathrm{N}_{\mathrm{y}}$ active layer was grown by magnetron reactive sputtering with $8 \mathrm{sccm}$ for $\mathrm{Ar}$ and $2 \mathrm{sccm}$ for $\mathrm{N}_{2}$ on 2-inch diameter (001) $p$-type silicon wafers. During the growth, the chamber base pressure was fixed at 3 mTorr and the substrate temperature was at room temperature (RT). Additional information on the growth process can be found in the following Reference 11.
Samples were deposited from $\mathrm{CeO}_{2}, \mathrm{Al}$ and $\mathrm{Si}$ targets with density of power varied from 0 to $2.1 \mathrm{~W} . \mathrm{cm}^{-2}, 0.3$ to $0.75 \mathrm{~W} . \mathrm{cm}^{-2}$ and fixed at $4.5 \mathrm{~W} / \mathrm{cm}^{2}$, respectively. As-deposited films were then thermally annealed in the $600^{\circ} \mathrm{C}$ to $1200^{\circ} \mathrm{C}$ temperature range for $1 \mathrm{~h}$, in nitrogen atmosphere at ambient pressure.

Device fabrication.-Figure 1 illustrates the typical fabricated device structure with the indicated specific layers thicknesses. The individual indium tin oxide (ITO) top electrical contacts were deposited on the $\mathrm{SiO}_{\mathrm{x}} \mathrm{N}_{\mathrm{y}}: \mathrm{Ce}^{3+}$ layer by electron beam evaporation using a shadow mask having a set of circular holes with a diameter of $200 \mu \mathrm{m}$. $\mathrm{In}_{2} \mathrm{O}_{3} / \mathrm{SnO}_{2}(90 \% / 10 \%)$ pellets with a diameter of $1 \mathrm{~mm}$ or $2 \mathrm{~mm}$ were used as sputtering targets. An oxygen flux was maintained in the sputtering chamber during deposition cycle to prevent the formation of oxygen defects in the transparent conducting layer, which would potentially cause EL from ITO layer. The ITO layer thickness was $200 \mathrm{~nm}$. The $\mathrm{SiO}_{\mathrm{x}} \mathrm{N}_{\mathrm{y}}: \mathrm{Ce}^{3+} / \mathrm{ITO}$ structure was heated up at a ramp rate of $15^{\circ} \mathrm{C} / \mathrm{min}$ from RT to $600^{\circ} \mathrm{C}$ and annealed for $1 \mathrm{~h}$ in a nitrogen atmosphere at ambient pressure. The bottom metal contact, a 200-nm-thick Al layer, was deposited at RT on the back of the silicon substrate.

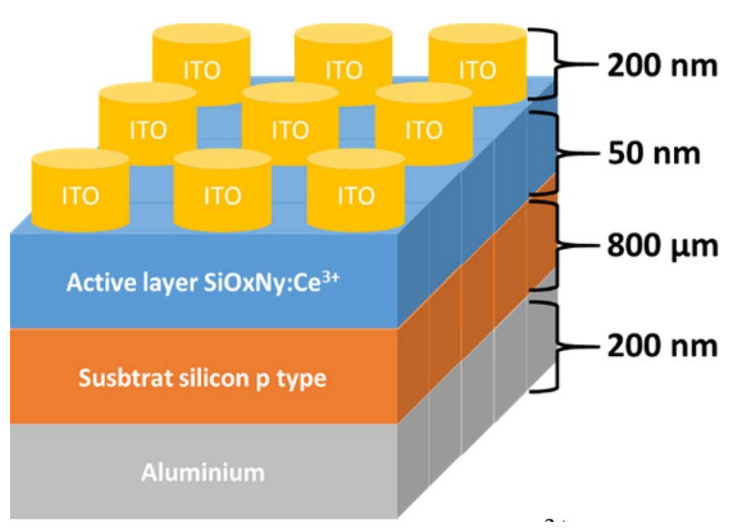

Figure 1. Schematic layout of fabricated $\mathrm{Al} / p-\mathrm{Si} / \mathrm{SiO}_{\mathrm{x}} \mathrm{N}_{\mathrm{y}}: \mathrm{Ce}^{3+} / \mathrm{ITO}$ device. 
Table I. Growth parameters used for depositing different Ce-doped $\mathrm{SiO}_{\mathrm{x}} \mathrm{N}_{\mathrm{y}}$ layers.

$\begin{array}{lcccc}\text { Sample Set } & \text { Nitrogen flux (sccm) } & \text { Thickness }(\mathrm{nm}) & \text { Ce concentration (at. \%) } & \text { Al concentration (at. \%) } \\ \text { S1 } & 1 & 47 & 6 & 0 \\ \text { S1 } & 1.5 & 50 & 6 & 0 \\ \text { S1 } & 2 & 51 & 2 & 0 \\ \text { S2 } & 2 & 49 & 4 & 0 \\ \text { S2 } & 2 & 48 & 6 & 0 \\ \text { S2 } & 2 & 51 & 6 & 0 \\ \text { S3 } & 2 & 51 & 6 & 3.0 \\ \text { S3 } & 2 & 54 & 6 & 8.5\end{array}$

Chemical, optical and electrical characterizations.-The chemical composition of the $\mathrm{SiO}_{\mathrm{x}} \mathrm{N}_{\mathrm{y}}: \mathrm{Ce}^{3+}$ films was determined by Rutherford Backscattering Spectroscopy (RBS) measurements carried out with a $4.5 \mathrm{MV}$ tandem accelerator. More details on RBS characterization are available elsewhere. ${ }^{11}$

The as-deposited films thicknesses were measured with a UVISEL VIS-FGMS Ellipsometer at $70^{\circ}$ incident angle. A Lot-Oriel, $1 \mathrm{~kW}$ Xenon lamp source having excitation optical beam diameter of $50 \mathrm{~nm}$, connected to an OMNI300 monochromator was used to excite the samples at $325 \mathrm{~nm}$ for the PL measurements. The detection system was locked-in with a SR830 lock-in amplifier referenced at the chopped excitation light beam frequency. Before depositing the electrical contacts, PL spectra were always obtained to confirm the $\mathrm{Ce}^{3+}$ ion optical activity.

$I-V$ curves were measured at RT by means of an Agilent B1500 semiconductor device analyzer connected to a Microtech Summit 11000 probe station. The EL spectra were acquired using a Princeton Instrument $\mathrm{LN}_{2}$-cooled CCD coupled to a monochromator. Three sets of samples were fabricated and their specifics are described in detail below.

Sets description.-Table I summarizes the different parameters used as well as the thicknesses of the deposited layers. The first set of samples (S1) was deposited under a tuned nitrogen flux from 1 to $2 \mathrm{sccm}$, the argon flux and plasma pressure being fixed at $8 \mathrm{sccm}$ and 3 mTorr, respectively. A power density of $2.1 \mathrm{~W} / \mathrm{cm}^{2}$ was applied on the $\mathrm{CeO}_{2}$ target. The second set (S2) was grown with a $2 \mathrm{sccm}$ nitrogen flux and a $8 \mathrm{sccm}$ argon flux at RT. The power density on the $\mathrm{CeO}_{2}$ target was varied in order to obtain various cerium dopings of 2 at. $\%, 4$ at. $\%$ and 6 at. $\%$. The third set (S3) was grown with a $2 \mathrm{sccm}$ nitrogen flux and a $8 \mathrm{sccm}$ argon flux when maintaining a 6 at. $\%$ cerium doping. The power density on the $\mathrm{Al}$ target was varied in order to obtain aluminum dopings of 3 at. $\%$ and 8.5 at. $\%$.

\section{Results and Discussion}

Composition and concentration (Set S2).-Depending on the growth conditions, the $\mathrm{SiO}_{\mathrm{x}} \mathrm{N}_{\mathrm{y}}: \mathrm{Ce}^{3+}$ films have various contents of $\mathrm{Si}, \mathrm{O}, \mathrm{N}$ and $\mathrm{Ce}$. These concentrations were investigated by RBS and reported previously. ${ }^{13}$ As an example, Table II summarizes all these concentrations of $\mathrm{SiO}_{\mathrm{x}} \mathrm{N}_{\mathrm{y}}: \mathrm{Ce}^{3+}$ films grown with different Ce contents and with a $2 \mathrm{sccm}$ nitrogen (Set S2).

Nitrogen variation (Set S1).-CThe nitrogen flux applied during the growth was found to be a dominant factor for $\mathrm{Ce}^{3+}$ ions emission in $\mathrm{SiO}_{\mathrm{x}} \mathrm{N}_{\mathrm{y}}$ as well as the $\mathrm{Si}$ concentration. Indeed, the nitrogen flux was established to have a direct impact on the Si concentration. ${ }^{11}$ Figure 2 shows the PL spectra obtained with an excitation wavelength of $340 \mathrm{~nm}$, for three films grown with different nitrogen fluxes $(1,1.5$ and $2 \mathrm{sccm}$ ) and a constant power density of $2.1 \mathrm{~W} / \mathrm{cm}^{2}$ on the $\mathrm{CeO}_{2}$ target.

For nitrogen fluxes of 1 and $1.5 \mathrm{sccm}$, a wide emission peak is observed from $400 \mathrm{~nm}$ to $600 \mathrm{~nm}$ corresponding to $\mathrm{Ce}^{3+}$ ions emission. For the highest nitrogen flux ( $2 \mathrm{sccm})$, a three times stronger emission is obtained. A previous study on the same material but with lower oxygen concentrations (around 10 at. \% of $\mathrm{O}$ ) showed the same $\mathrm{Ce}^{3+}$ ion emission for a $2 \mathrm{sccm} \mathrm{N} \mathrm{N}_{2}$ flux. ${ }^{11}$ However, in this latter, no emission for samples grown with fluxes under $2 \mathrm{sccm}$ of $\mathrm{N}_{2}(0.75 \mathrm{sccm}, 1 \mathrm{sccm})$ was observed. Consequently, the emergence of an emission for lower nitrogen flux in this study could come from the important oxygen presence (20 to 30 at. \% here vs 10 at. \% in Ref. 10) that favors the cerium emission.

Ce concentration variation (Set S2).--Figure 3 shows the PL spectra of Ce-doped $\mathrm{SiO}_{\mathrm{x}} \mathrm{N}_{\mathrm{y}}$ layers containing $\mathrm{Ce}^{3+}$ ions with cerium concentrations between 2,4 and 6 at.\%, all grown with the same nitrogen

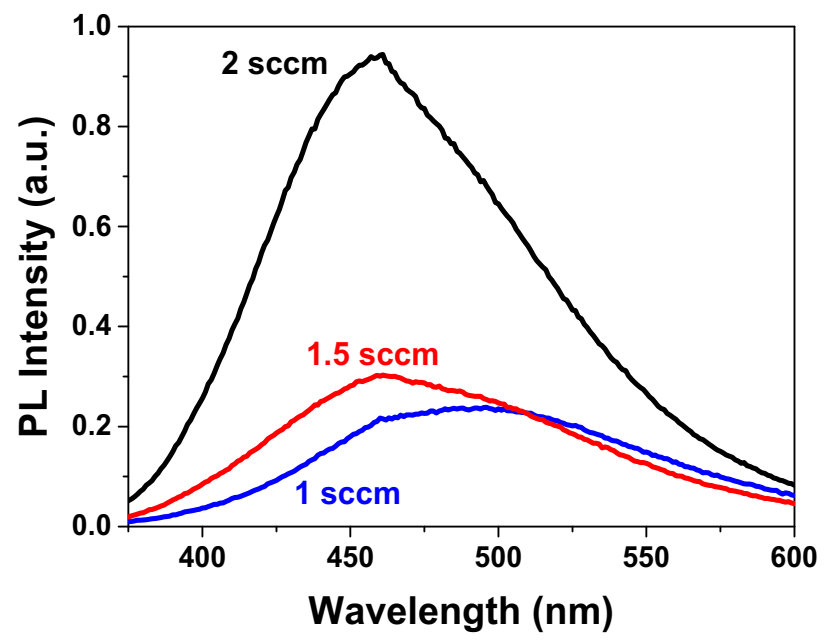

Figure 2. PL spectra for the 6 at. $\%$ Ce-doped $\mathrm{SiO}_{\mathrm{x}} \mathrm{N}_{\mathrm{y}}$ layer grown under 1 , 1.5 and $2 \mathrm{sccm}$ nitrogen fluxes excited at $340 \mathrm{~nm}$ wavelength at RT.

Table II. Si, O, N and Ce concentrations obtained by RBS for the Set S2.

\begin{tabular}{|c|c|c|c|c|c|}
\hline Density of power $\left(\mathrm{W} / \mathrm{cm}^{2}\right)$ & Nitrogen flux (sccm) & $\mathrm{Si}$ (at. \%) & $\mathrm{O}($ at. $\%)$ & $\mathrm{N}($ at. \%) & $\mathrm{Ce}$ (at. \%) \\
\hline 1.05 & 2 & 38.7 & 18.9 & 39.7 & 2 \\
\hline 1.50 & 2 & 37.6 & 19.3 & 38.6 & 4 \\
\hline 2.10 & 2 & 31.3 & 31.3 & 31.3 & 6 \\
\hline
\end{tabular}




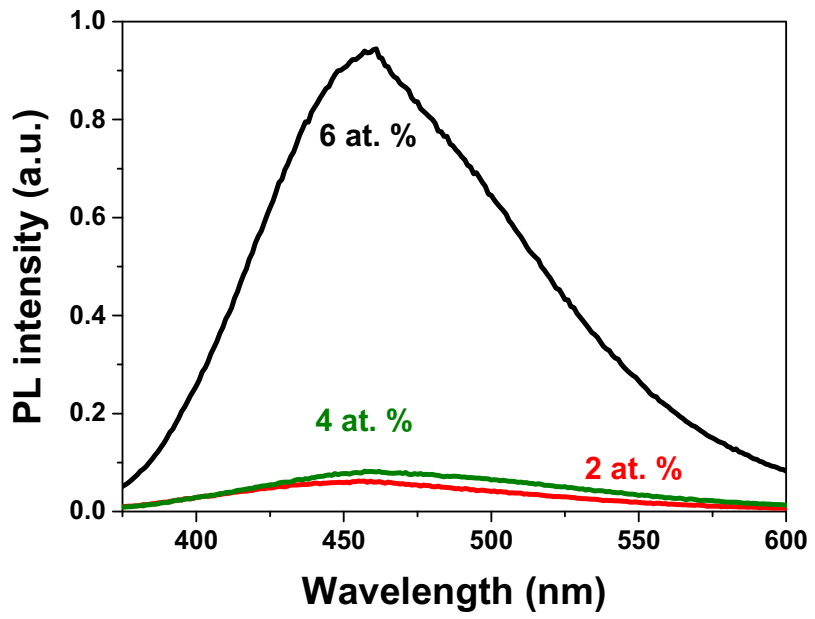

Figure 3. PL spectra of Ce-doped $\mathrm{SiO}_{\mathrm{x}} \mathrm{N}_{\mathrm{y}}$ layers grown with 2,4 and 6 at. \% of Ce under $2 \mathrm{sccm}$ nitrogen flux excited at $340 \mathrm{~nm}$ wavelength at $300 \mathrm{~K}$.

flux of $2 \mathrm{sccm}$. It is observed that the PL intensity increases drastically by an order of magnitude when Ce content increased up to 6 at. $\%$.

Al concentration variation (Set S3).--To improve the conductivity in the EL experiments, ${ }^{14}$ optimized Ce-doped $\mathrm{SiO}_{\mathrm{x}} \mathrm{N}_{\mathrm{y}}$ samples doped with 6 at.\% were co-doped with Aluminum (Figure 4). It is found that visible emission intensity decreases when $\mathrm{Al}$ content increases up to 3 at. $\%$ and then increases for samples having up to 8.5 at.\% of $\mathrm{Al}$. Further studies are required to investigate this behavior, because with high concentration of $\mathrm{Al}$, the host matrix could increase the optical reflection at the interface film/substrate and then artificially increase the PL intensity. ${ }^{15}$ In any case, the $\mathrm{Al}$ doping seems to reduce the PL activity.

After demonstrating that $\mathrm{Ce}^{3+}$ ions are optically active under $340 \mathrm{~nm}$-excitation wavelength in Ce-doped $\mathrm{SiO}_{\mathrm{x}} \mathrm{N}_{\mathrm{y}}$ samples, electrical contacts were achieved as described in the experimental section. In the following of this article, we will focus on the electrical excitation of $\mathrm{Ce}^{3+}$ ions in $\mathrm{SiO}_{\mathrm{x}} \mathrm{N}_{\mathrm{y}}$ matrices grown with different nitrogen fluxes (Set $\mathrm{S} 1$ ), followed by the $\mathrm{SiO}_{\mathrm{x}} \mathrm{N}_{\mathrm{y}}$ matrices grown with different $\mathrm{Ce}^{3+}$ concentrations (Set S2) and in Al-co-doped $\mathrm{SiAlO}_{\mathrm{x}} \mathrm{N}_{\mathrm{y}}$ matrices with various $\mathrm{Al}$ contents (Set $\mathrm{S} 3$ ).

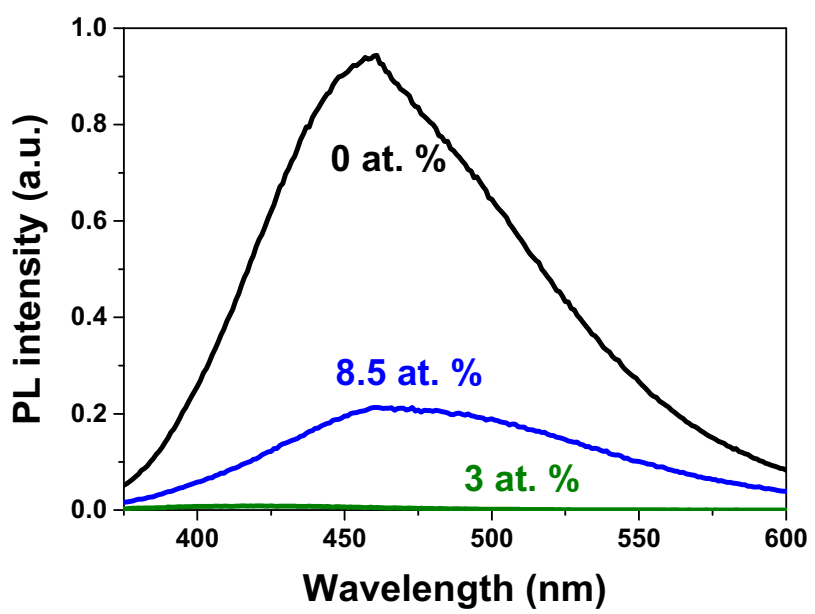

Figure 4. PL spectra of Ce-doped $\mathrm{SiAlO}_{\mathrm{x}} \mathrm{N}_{\mathrm{y}}$ layers grown with $0,3.0$ and 8.5 at. $\%$ of $\mathrm{Al}$ and with 6 at. \% of Ce under $2 \mathrm{sccm}$ nitrogen flux excited at $340 \mathrm{~nm}$ wavelength at $300 \mathrm{~K}$.
Electroluminescence.-Nitrogen concentration variation (Set S1).-All samples have an active thickness of about $50 \mathrm{~nm}$. This thickness implies a low potential barrier height favoring the electrical conduction. A preliminary $I-V$ characterization was performed on the devices with a voltage bias between $0 \mathrm{~V}$ to $\sim-40 \mathrm{~V}$. The $J(E)$ plot is represented with $\boldsymbol{J}=\frac{I}{\pi r^{2}}$ and $\boldsymbol{E}=\frac{V}{d}$, respectively, where $I$ is the measured current, $r$ is the surface contact radius, $V$ is the voltage and $d$ is the layer thickness. Because the silicon wafers used for the substrates are $p$-doped, thus the current conduction across the structure is more efficient when negatively biased. Therefore, only this case will be discussed hereafter.

Figure 5a displays the $J(E)$ curves for the three Ce-doped $\mathrm{SiO}_{\mathrm{x}} \mathrm{N}_{\mathrm{y}}$ layers grown with nitrogen fluxes of $1,1.5$ and $2 \mathrm{sccm}$, respectively. The curves are homogenous with a slight increase of the current density starting at $1.6 \mathrm{MV} / \mathrm{cm}$ for the samples grown with lower nitrogen fluxes whereas a strong current density increase is observed at $0.5 \mathrm{MV} / \mathrm{cm}$ for the sample grown with a nitrogen flux of $2 \mathrm{sccm}$. The $J(E)$ curve corresponding to the layer grown with $1.5 \mathrm{sccm}$ nitrogen flux shows an intermediate behavior, namely, for a low electric field, the increase of current density follows the behavior of the lowest flux and after a field of $2 \mathrm{MV} / \mathrm{cm}$, its behavior follows the curve corresponding to a $2 \mathrm{sccm}$ nitrogen flux. All devices breakdown when the electric field applied reached $6 \mathrm{MV} / \mathrm{cm}$, as shown in the Fig. $5 \mathrm{~b}$.

In Silicon-based matrices, the conduction mechanisms usually observed are Fowler Nordheim tunneling (FNT),${ }^{16}$ trap assisted tunneling $(\mathrm{TAT})^{17,18}$ or Pool-Frenkel (PF) emission. ${ }^{19}$ The tunneling processes considered are schematically illustrated in Fig. 6.

Their respective current densities of these processes (i.e. $J_{F N T}, J_{T A T}$ and $\left.J_{P F}\right)$ as a function of the electric field $(E)$ are expressed by the Eqs. 1-3:

$$
J_{F N}=\frac{q^{3}}{16 \pi^{2} \hbar m_{o x} \Phi_{b}} E^{2} \exp \left(\frac{-4 \sqrt{2 m^{*}} \Phi_{b}^{\frac{3}{2}}}{3 q \hbar E}\right)
$$

with $m_{\mathrm{ox}}$ the electron effective mass in the dielectric, $\phi_{b}$ the potential barrier between the electrode and the conduction band and $m^{*}$ the electron effective mass,

$$
J_{T A T}=\frac{q n_{t}}{2 \tau} \exp \left(\frac{-4 \sqrt{2 m^{*}} \Phi_{t}^{\frac{3}{2}}}{3 q \hbar E}\right)
$$

with $n_{\mathrm{t}}$ the trap surface density, $t$ the relaxation time between 2 tunnel effects (i.e. capture and emission) and $\Phi_{t}$ the energy of the trap in comparison to the conduction band, and

$$
J_{P F}=q \mu N_{c} E \exp \left(\frac{\Phi_{t}-\sqrt{\frac{q^{3} E}{\pi \varepsilon_{0} \varepsilon_{r}}}}{k_{B} T}\right)
$$

where $\mu$ is the carrier mobility, $N_{\mathrm{c}}$ the density of states, $\phi_{\mathrm{t}}$ the electrodedielectric barrier, $\varepsilon_{\mathrm{r}}$ the relative permittivity and $T$ the temperature.

By conducting theoretical modeling using Eqs. 1-3, we have concluded that for active layers grown with the higher nitrogen fluxes (1.5 and $2 \mathrm{sccm}$ ), the conduction mechanism obeys the PF model (see Fig. 5a). Indeed for the two others models (TAT and FN), the coefficient of determination (adjusted $\mathrm{R}^{2}$ ) was lower than for PF model $\left(\mathrm{R}^{2} \simeq 0.9999\right)$. For this mechanism, the carrier transport is done by trap charges released at the conduction band and trapped by another level. It happens again and again until they reach the opposite electrode. ${ }^{15} \mathrm{In}$ this case, the temperature plays an important role as the thermal energy allows electrons to acquire sufficient energy to reach the conduction band. The PF model can be applied satisfactorily to a material with defects similar to those observed in a nitride matrix. Indeed amorphous $\mathrm{SiN}_{\mathrm{x}}$ layers shows a high defect density with energies treated either as distributed localized states or band tail states. ${ }^{20-22}$

Figure $5 \mathrm{c}$ shows electrical conductivity $(\sigma)$ according to the voltage through the Ce-doped $\mathrm{SiO}_{\mathrm{x}} \mathrm{N}_{\mathrm{y}}$ active layer measured at $300 \mathrm{~K}$. It can be seen that the conductivity curves obtained for layers grown with different nitrogen fluxes show two distinct effects as the bias voltage 

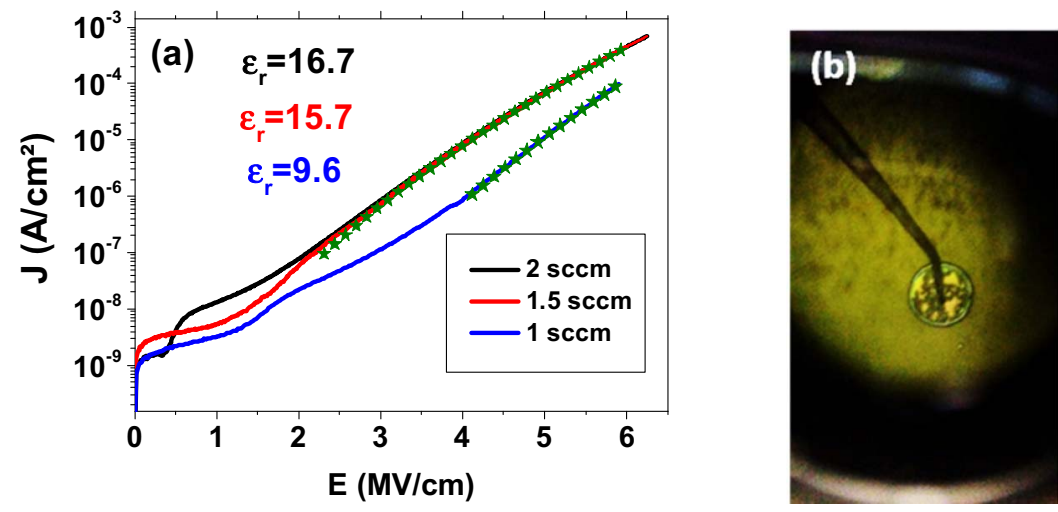

Figure 5. (a) Current density of Ce-doped $\mathrm{SiO}_{\mathrm{x}} \mathrm{N}_{\mathrm{y}}$ layers grown with different nitrogen fluxes as a function of the applied electric field (negative polarization) and the corresponding fit to the Poole-Frenkel conduction mechanism model (symbol). (b) Optical image of the surface of an electroluminescence device after breakdown has occurred. (c) Conductivity $\sigma(J / E)$ vs. external

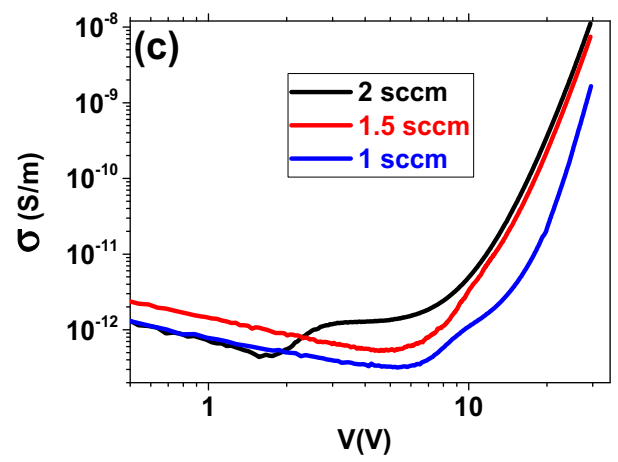
voltage applied.

is increased. First, the lowest voltage threshold $(2 \mathrm{~V})$ is observed for the $2 \mathrm{sccm}$ nitrogen flux as compared to the two other nitrogen fluxes $(8 \mathrm{~V})$. In addition, the conductivity is an increasing function of the nitrogen rate. Indeed, in a previous study ((11), Figure 7), it has been shown that the higher nitrogen flux during the deposition inside the chamber, the more $\mathrm{N}$ is included inside the film in detriment of the $\mathrm{Si}$ element. Then, because the gap of the host matrix is reduced due to this higher content of nitrogen $\left(\mathrm{SiO}_{2}(\approx 9 \mathrm{eV})=>\mathrm{Si}_{3} \mathrm{~N}_{4}(\approx 4-5 \mathrm{eV})\right)$, the conductivity is increased.

Figure 7 shows the EL spectrum of Ce-doped $\mathrm{SiO}_{\mathrm{x}} \mathrm{N}_{\mathrm{y}}$ layer grown with a $2 \mathrm{sccm}$ nitrogen flux. A relatively low intensity emission band was detected at $300 \mathrm{~K}$ centered at $500 \mathrm{~nm}$ due to $4 f-5 d$ transitions in the $\mathrm{Ce}^{3+}$ ion. This EL peak is similar to the one observed in PL spectra (see Fig. 2), allowing us to believe that in both cases, the same optically active center is involved. It should be noted that no EL was detected for the Ce-doped $\mathrm{SiO}_{\mathrm{x}} \mathrm{N}_{\mathrm{y}}$ layers grown with 1 and $1.5 \mathrm{sccm}$ nitrogen fluxes.

Cerium concentration variation (Set S2).-Figure 8a displays the $J(E)$ curves of $\mathrm{Ce}$-doped $\mathrm{SiO}_{\mathrm{x}} \mathrm{N}_{\mathrm{y}}$ layers with the three different $\mathrm{Ce}$ concentrations. In all cases, the $J(E)$ curves are similar and can be modeled by the PF mechanism, which is coherent with the fit of the set $\mathrm{S} 1$. We have extracted the dielectric constants $\left(\varepsilon_{r}\right)$ for each tested Ce-doped $\mathrm{SiO}_{\mathrm{x}} \mathrm{N}_{\mathrm{y}}$ layer by fitting to the PF model.

Our $\varepsilon_{r}$ values are found between $14.5 \pm 1$ to $16.7 \pm 1$. They increase slightly with the Ce content, however, the observed $\varepsilon_{r}$ increase by $\sim 7 \%$ is not significant, taking account the uncertainties. Nevertheless, these measurements seem to highlight that the total amount

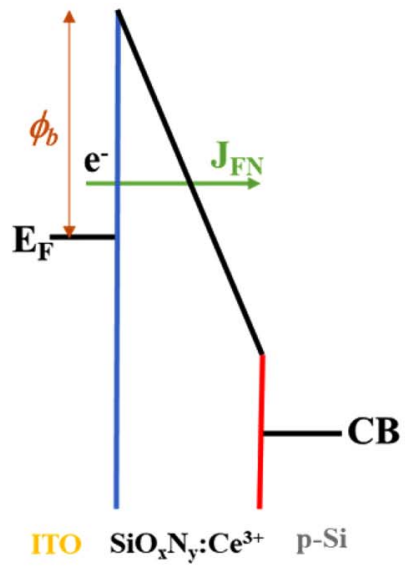

(a)

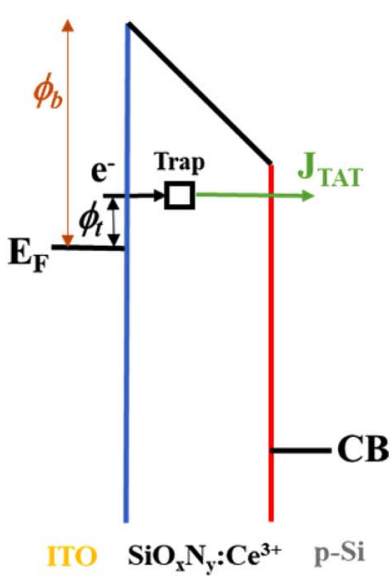

(b)

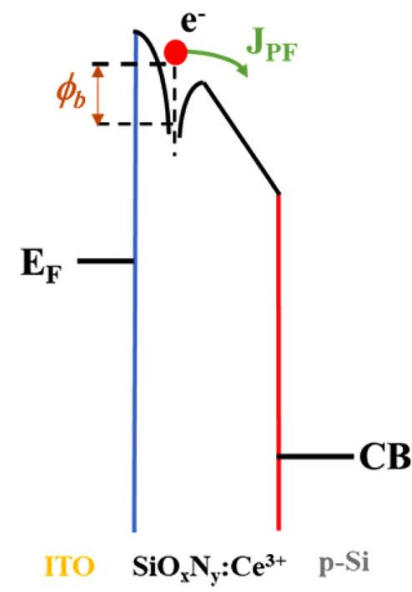

(c)

Figure 6. Schematic illustrations of conduction mechanisms considered in our devices. (a) Fowler Nordheim tunneling (FNT), (b) trap assisted tunneling (TAT) and (c) Pool-Frenkel (PF) emission. 


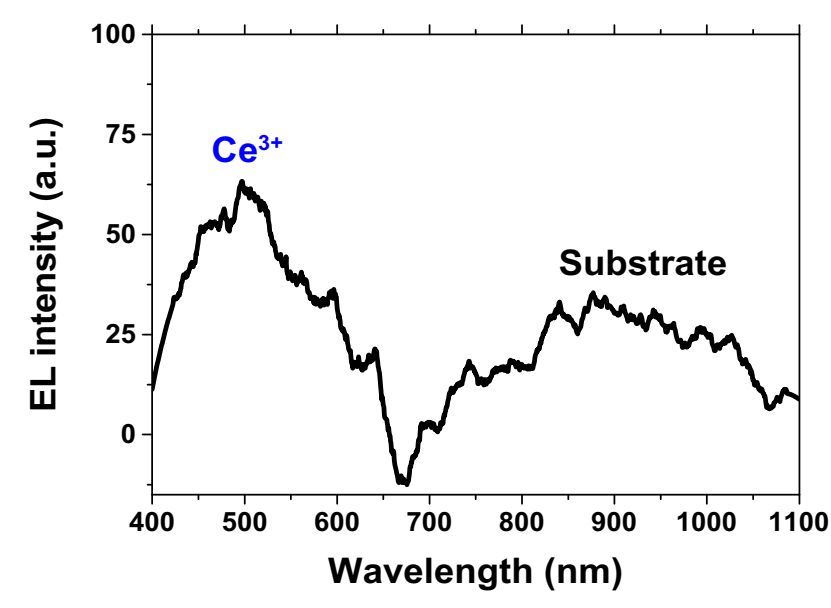

Figure 7. EL spectrum from Ce-doped $\mathrm{SiO}_{\mathrm{x}} \mathrm{N}_{\mathrm{y}}$ layer with 6 at. \% of Ce growth under a $2 \mathrm{sccm}$ nitrogen flux measured at $300 \mathrm{~K}$.

of RE incorporated does not change the dielectric constant despite the matrix composition modification. Indeed, the mean $\varepsilon_{r}$ values is almost 15. Ramirez found dielectric constant values between 8 and 13 for these devices of Ce-doped oxynitride silicon ${ }^{20}$ which are much lower than ours. It should be kept in mind that the less oxygen in the deposited films, the higher the refractive index of this film. Then, in first approximation, for the same film quality, the dielectric constant is higher too with less oxygen. Considering the same $\mathrm{Si}(\approx 35$ at. \%) and $\mathrm{N}(\approx 35$ at. $\%)$ concentrations, we have less oxygen $(\approx 20$ at. $\%)$ compared to the Ramirez devices ( $\approx 40$ at. $\%$ ), which can explain our higher values for the dielectric constant.

Figure $8 \mathrm{~b}$ displays the evolution of the conductivity $(\sigma)$ as a function of Ce-doping content. The conductivity does not depend significantly on the $\mathrm{Ce}^{3+}$ concentration. In other words, the Ce dopant does not seem to play a significant role on $\mathrm{Ce}$-doped $\mathrm{SiO}_{\mathrm{x}} \mathrm{N}_{\mathrm{y}}$ active layer conductivity.

As seen in Figure 8a, the device at 6 at. \% broke down at an electric field of $6 \mathrm{MV} / \mathrm{cm}$, whereas the 4 at $\%$ tend to reach $8 \mathrm{MV} / \mathrm{cm}$.

We have recorded EL spectra for devices with active layers doped with 4 and 6 at. \% of Ce. The 2 at. \% Ce thin film EL was undetectable. Figure 9 shows comparison between EL spectra recorded under the same excitation conditions before the breakdown of the device and the corresponding $\mathrm{PL}$ spectrum from a Ce-doped $\mathrm{SiO}_{\mathrm{x}} \mathrm{N}_{\mathrm{y}}$ layer with $\mathrm{Ce}$ content of 4 at.\%. Surprisingly, the EL intensity related to 6 at. \% $\mathrm{Ce}$ is very low, whereas the maximum PL intensity corresponds to this concentration (Figure 3). We speculate that the breakdown in devices with active layers containing high $\mathrm{Ce}$ content is possibly due to the

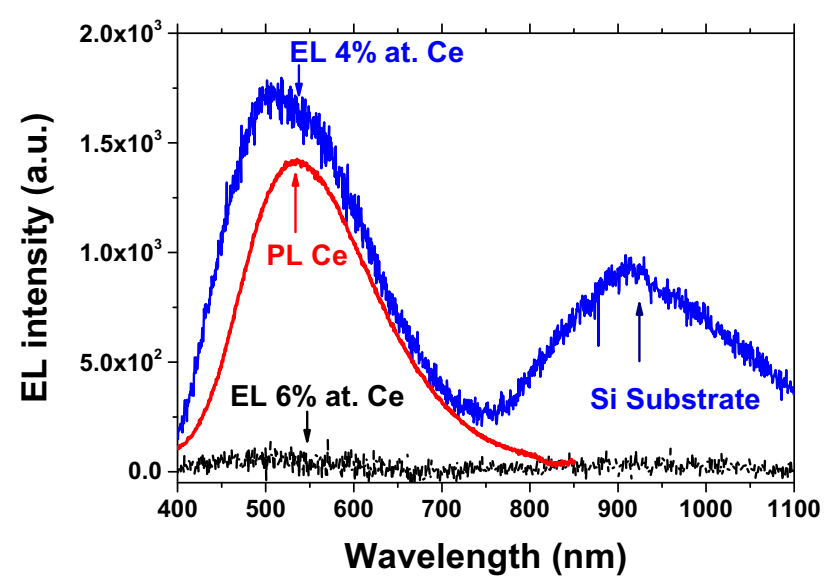

Figure 9. Comparison between EL spectra for Ce-doped $\mathrm{SiO}_{\mathrm{x}} \mathrm{N}_{\mathrm{y}}$ active layers having 4 or 6 at. \% of Ce grown under a $2 \mathrm{sccm}$ nitrogen flux and PL spectrum of the Ce-doped $\mathrm{SiO}_{\mathrm{x}} \mathrm{N}_{\mathrm{y}}$ layer with 4 at. \% of Ce excited at $340 \mathrm{~nm}$ wavelength at $300 \mathrm{~K}$.

contact failure as the selected tested electroluminescent devices failed before achieving sufficient current to generate strong EL signal.

The observed EL spectrum is about $200 \mathrm{~nm}$ wide with a maximum peak intensity at $500 \mathrm{~nm}$. This dominant EL spectrum band shape is similar to the PL spectrum obtained for the same active layer confirming that the observed emission originates from the $\mathrm{Ce}^{3+}$ ion. It is seen that the EL peak maximum is redshifted $(\sim 50 \mathrm{~nm})$ as compared to the EL spectra. This featue was also reported for similar devices by Ramirez et al. ${ }^{10}$ and Skopura et al. ${ }^{2}$ This shift could come from the nephelauxetic effect and the ligand-field splitting of the $5 \mathrm{~d}$ band, ${ }^{11,24}$ resulting from the introduction of nitrogen into $\mathrm{SiO}_{\mathrm{x}} \mathrm{N}_{\mathrm{y}}$ matrix inducing a $\mathrm{Ce}^{3+}$ ion emission band maximum redshift.

Al concentration variation (Set S3).-Figure 10 shows the $J(E)$ curves of Ce-doped $\mathrm{SiAlO}_{\mathrm{x}} \mathrm{N}_{\mathrm{y}}$ active layers doped with $\mathrm{Al}$ at $0,3.0$ and 8.5 at. \% concentration and a fixed 6 at. $\%$ of Ce. It is seen that the current density starts to increase as soon as the electric field is applied. This observation is in direct contrast to the behavior of Al-free active layers where current density increased when the applied electric field exceeded $0.5 \mathrm{MV} / \mathrm{cm}$ (see Fig. 8). We observe that by incorporating 3.0 at $\%$ and 8.5 at.\% $\mathrm{Al}$ dopants in the active layers, the breakdown occurs for electric fields of $7.5 \mathrm{MV} / \mathrm{cm}$ and $9 \mathrm{MV} / \mathrm{cm}$, respectively. It is clear that incorporating $\mathrm{Al}$ increases the conductivity of the active layer only at lower bias voltages between 0 to $4 \mathrm{~V}$ as seen in Fig. 10b. For higher bias voltages (from $4 \mathrm{~V}$ to $40 \mathrm{~V}$ ), the conductivity of active layers is significantly reduced, compared with the undoped layer. Thus,
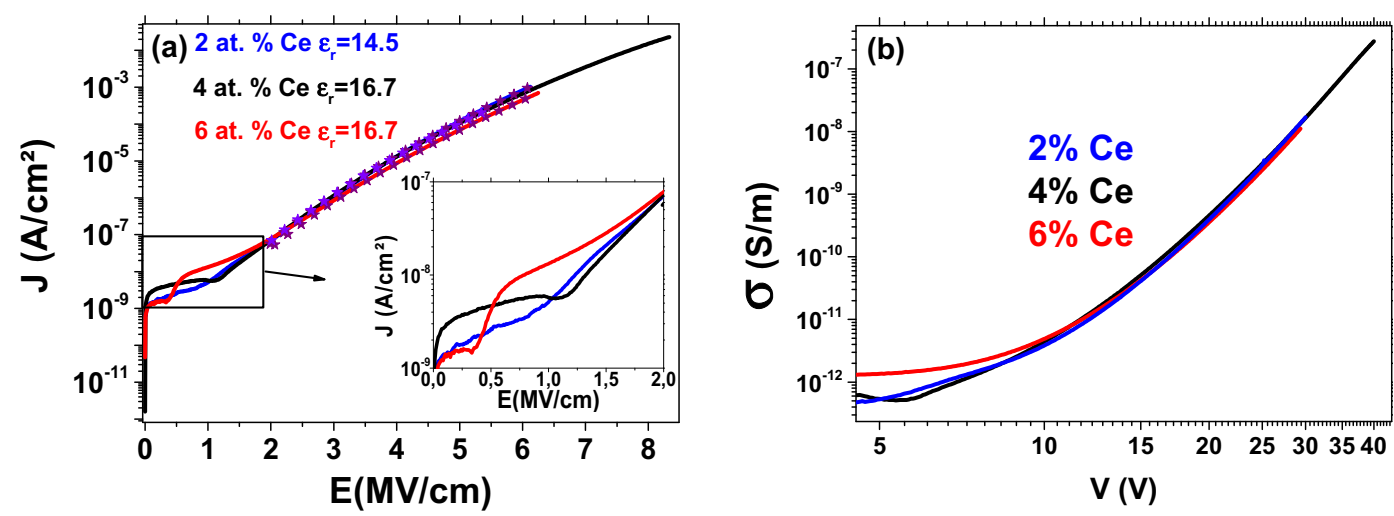

Figure 8. (a) Current density vs. applied field (negative polarization) in Ce-doped $\mathrm{SiO}_{\mathrm{x}} \mathrm{N}_{\mathrm{y}}$ active layers grown with different Ce contents. Please note that devices with active layers having 2 at. \% and 6 at. \% of Ce broke down when the electric field exceeded $6 \mathrm{MV} / \mathrm{cm}$. The stars on dashed line correspond to the PF fitting. The insert shows a zoom in $J(E)$ curves for the lowest $\mathrm{E}$ values. (b) Plot of the conductivity vs. applied voltage for the same active layers as in (a). 

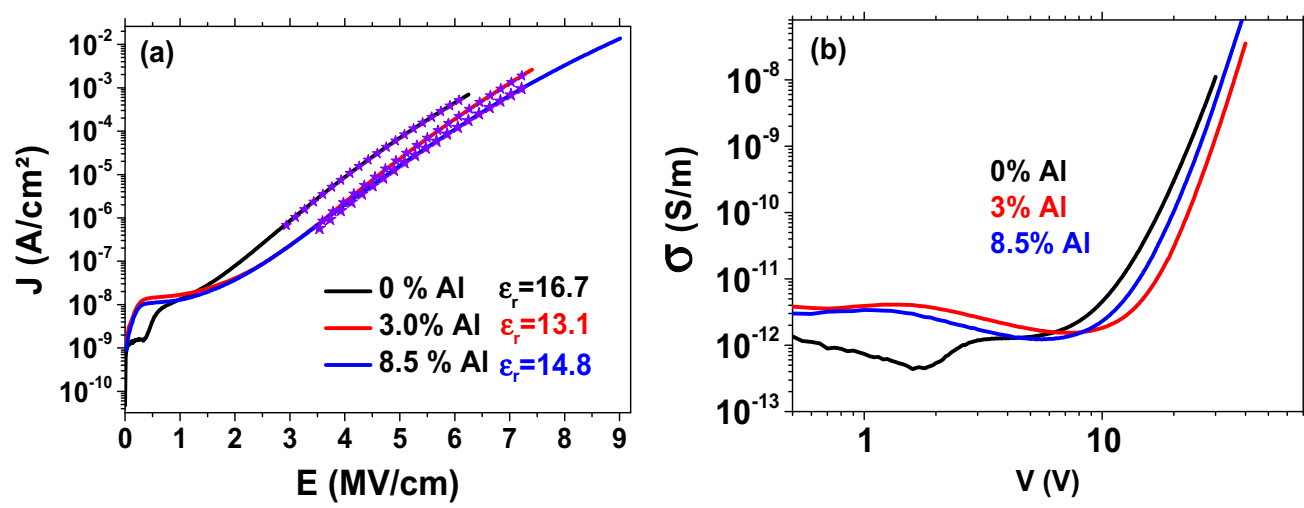

Figure 10. (a) Current density vs. applied electric field (negative polarization) for Ce-doped $\mathrm{SiAlO}_{\mathrm{x}} \mathrm{N}_{\mathrm{y}}$ layers grown with different $\mathrm{Al}$ contents and 6 at. \% of Ce. Stars on dashed lines are fits to individual experimental curves using the PF model. (b) Conductivity $\sigma$ vs. applied voltage for the same active layers as in (a).

by $\mathrm{Al}$ doping, one can achieve a device with a breakdown threshold occuring at higher bias voltages, but surprisingly at the same time, $\mathrm{Al}$ doping does not improve the overall active layer conductivity.

As seen in Fig. 10a, all $J(E)$ curves show the same behavior that can be simulated again by the PF mechanism. The dielectric constant $\left(\varepsilon_{r}\right)$ values of $16.7,13.1$ and 14.8 were extracted from the fitting. Taking into account the uncertainties, the PF fittings could not evidence the effect of the variation of the Al concentration.

Figure 11 displays the EL spectra of $\mathrm{Al}$ co-doped $\mathrm{SiO}_{\mathrm{x}} \mathrm{N}_{\mathrm{y}}: \mathrm{Ce}^{3+}$ (6 at. \%) active layers along with a reference Al-free counterpart. It is seen that the most intense EL spectrum is obtained for the $\mathrm{SiO}_{\mathrm{x}} \mathrm{N}_{\mathrm{y}}$ : $\mathrm{Ce}^{3+}$ active layer co-doped with 3 at. $\% \mathrm{Al}$. There is three times more current passing through this sample as compared to the sample containing 8.5 at. \% of Al. We explain this difference in the EL intensity by the fact that, for these high voltage values, the Ce ion could be excited by impact excitation, as demonstrated for $\mathrm{Er}^{3+}$ ions in the same host matrices. $^{20,25}$ Then, due to the fact that the conductivity is increased for 8.5 at. $\%$ of $\mathrm{Al}$. at $42 \mathrm{~V}$ compared to 3 at. \% of Al. (Figure 10b), this excitation is reduced and could explain the reduction of the EL signal.

\section{Conclusions}

All studied samples have been first tested for their optical activity under optical excitation and showed $\mathrm{Ce}^{3+}$ ions PL signature. Then, regarding the influence of nitrogen flow on EL measurements, no signal was observed for layers grown under 1 and $1.5 \mathrm{sccm}$. However, a

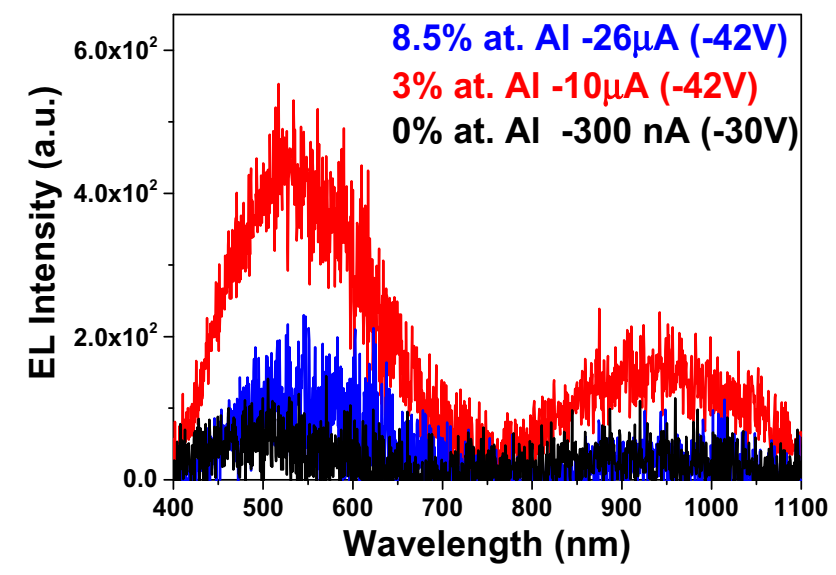

Figure 11. EL spectra of Ce-doped $\mathrm{SiAlO}_{\mathrm{x}} \mathrm{N}_{\mathrm{y}}$ active layers containing 0,3 and 8.5 at. $\%$ of $\mathrm{Al}$ grown under a $2 \mathrm{sccm}$ nitrogen flux obtained under excitation condition listed in insert. The EL band peaking at $950 \mathrm{~nm}$ corresponds to the Si substrate. weak EL signal was observed for the sample grown under a $2 \mathrm{sccm}$ nitrogen flux. A well-defined EL signal was obtained for a 4 at. \% Cedoped sample which demonstrates the potential application for blue LED through Ce doping. Incorporating $\mathrm{Al}$ to the $6 \% \mathrm{Ce}$ doped active layer permits an increase in the EL signal compared to the Al-free sample as well as increases the breakdown voltage. The same study should be performed on the $4 \%$ at. Ce doped sample to confirm this trend.

The electrical conductivity of the samples was best fitted to a Poole-Frenkel model. Hot carriers jump from defect-to-defect until they reach the conduction band with carriers being trapped in localized states. The change in dielectric constant or relative permittivity and conductivity is associated with the matrix composition and not the dopant concentration. EL spectroscopy measurements tested the emission of different $\mathrm{Si}(\mathrm{Al}) \mathrm{O}_{\mathrm{x}} \mathrm{N}_{\mathrm{y}}: \mathrm{Ce}^{3+}$ samples. Among all layers tested, only the samples deposited under a $2 \mathrm{sccm}$ nitrogen flux $\mathrm{SiO}_{\mathrm{x}} \mathrm{N}_{\mathrm{y}}: \mathrm{Ce}^{3+}(4$ at. $\%), \mathrm{SiAlON}: \mathrm{Ce}^{3+}(6$ at. $\% \mathrm{Ce}, 3$ at. $\% \mathrm{Al}$ and 8.5 at. \% Al) produced an EL signal. One of the main reasons for the efficiency of those layers is their high breakdown strength enabling the device to reach sufficient current for generating EL emission. By conducting Al co-doping, we were able to increase the tested samples breakdown threshold in order to obtain enhanced electroluminescence. Those results pave the way for enabling blue LED fabrication based on $\mathrm{SiO}_{\mathrm{x}} \mathrm{N}_{\mathrm{y}}: \mathrm{Ce}^{3+}$ layers; however, the growth parameters as well as the metal contacts fabrication methods should be further optimized.

\section{Acknowledgments}

The authors would like to thank Cédric Frilay from CIMAP Laboratory (Caen, France) for his great help on sample growth. This work was financially supported by the French Research National Agency through the GENESE project (N ANR-13-BS09-0020-01). W.M.J. acknowledges the support from the NSF CAREER Award no. DMR1056493.

\section{ORCID}

F. Ehré (10) https://orcid.org/0000-0001-7711-6712

\section{References}

1. M. Suyama, R. I. Laming, and D. N. Payne, Temperature dependent gain and noise characteristics of a $1480 \mathrm{~nm}$-pumped erbium-doped fibre amplifier. Electron. Lett., 26(21), 1756 (1990).

2. W. Skorupa, J. M. Sun, S. Prucnal, L. Rebohle, T. Gebel, A. N. Nazarov et al., Rare Earth Ion Implantation for Silicon Based Light Emission. Solid State Phenom., 108109, 755 (2005)

3. W. J. Miniscalco, Erbium-doped glasses for fiber amplifiers at $1500 \mathrm{~nm}$. J. Light Technol., 9(2), 234 (1991). 
4. R. S. Quimby, W. J. Miniscalco, and B. Thompson, Clustering in erbium-doped silica glass fibers analyzed using $980 \mathrm{~nm}$ excited-state absorption. J. Appl. Phys., 76(8), 4472 (1994).

5. L. Kokou and J. Du, Rare earth ion clustering behavior in europium doped silicate glasses: Simulation size and glass structure effect. J. Non-Cryst. Solids., 358(24), 3408 (2012)

6. S. Yerci, R. Li, and L. Dal Negro, Electroluminescence from Er-doped Si-rich silicon nitride light emitting diodes. Appl. Phys. Lett., 97(8), 081109 (2010).

7. L. Xu, S. Li, L. Jin, D. Li, and D. Yang, Temperature dependence of sensitized Er3+ luminescence in silicon-rich oxynitride films. Nanoscale Res. Lett., 9(1), 1 (2014).

8. Y. Q. Li, N. Hirosaki, R.-J. Xie, T. Takeda, and M. Mitomo, Photoluminescence properties of rare earth doped $\alpha-\mathrm{Si}_{3} \mathrm{~N}_{4}$. J. Lumin. Juill, 130(7), 1147 (2010).

9. D. J. DiMaria and J. R. Abernathey, Electron heating in silicon nitride and silicon oxynitride films. J. Appl. Phys., 60(5), 1727 (1986).

10. J. M. Ramírez, A. Ruiz-Caridad, J. Wojcik, A. M. Gutierrez, S. Estradé, F. Peiró et al., Luminescence properties of $\mathrm{Ce}^{3+}$ and $\mathrm{Tb}^{3+}$ co-doped SiOxNy thin films: Prospects for color tunability in silicon-based hosts. J. Appl. Phys., 119(11), 113108 (2016).

11. F. Ehré, C. Labbé, C. Dufour, W. M. Jadwisienczak, J. Weimmerskirch-Aubatin $\mathrm{X}$. Portier et al., The nitrogen concentration effect on $\mathrm{Ce}$ doped $\mathrm{SiO}_{\mathrm{x}} \mathrm{N}_{\mathrm{y}}$ emission: toward optimized $\mathrm{Ce}^{3+}$ for LED applications. Nanoscale, 10(8), 3823 (2018).

12. L. Koao, H. C. Swart, and F. B. Dejene, Effects of aluminum co-doping on photoluminescence properties of $\mathrm{Ce}^{3+}$-doped $\mathrm{SiO}_{2}$ glasses. J. Rare. Earths., 28, 206 (2010)

13. F. Ehré, Elaboration and characterization of cerium-ytterbium co-doped silicon oxynitride films: applications to light emitting devices and quantum cutting for solar cells. $\mathrm{PhD}$ thesis Caen, Normandy University, 2017.

14. Z. R. Nie, T. Jin, J. Fu, G. Xu, J. Yang, J. X. Zhou et al., Research on Rare Earth in Aluminum. Mater. Sci. Forum., 396-402, 1731 (2002).
15. L. Rebouta, A. Sousa, P. Capela, M. Andritschky, P. Santilli, A. Matilainen et al. Solar selective absorbers based on $\mathrm{Al}_{2} \mathrm{O}_{3}: \mathrm{W}$ cermets and AlSiN/AlSiON layers. Sol. Energy. Mater. Sol. Cells., 137, 93 (2015).

16. Z. A. Weinberg, J. Appl. Phys., 53, 552 (1982).

17. M. P. Houng, Y. H. Wang, and W. J. Chang, Current transport mechanism in trapped oxides: A generalized trap-assisted tunneling model. J. Appl. Phys., 86(3), 1488 (1999).

18. D. J. DiMaria and E. Cartier, Mechanism for stress-induced leakage currents in thin silicon dioxide films. J. Appl. Phys., 78(6), 3883 (1995)

19. H. C. de Graaff, M. Huybers, and J. G. de Groot, Grain boundary states and the characteristics of lateral polysilicon diodes. Solid-State Electron., 25(1), 67 (1982).

20. S. Cueff, J. Manel Ramírez, J. A. Kurvits, Y. Berencén, R. Zia, B. Garrido et al., Electroluminescence efficiencies of erbium in silicon-based hosts. Appl. Phys. Lett., 4 nov, 103(19), 191109 (2013).

21. M. Wang, M. Xie, L. Ferraioli, Z. Yuan, D. Li, D. Yang et al., Light emission properties and mechanism of low-temperature prepared amorphous $\mathrm{SiN}_{\mathrm{x}}$ films. I Room-temperature band tail states photoluminescence. J. Appl. Phys., 104(8), 083504 (2008).

22. S. Yerci, Li Rui, S. O. Kucheyev, T. van Buuren, S. N. Basu, and Negro L. Dal, Visible and $1.54 \mu \mathrm{m}$ Emission From Amorphous Silicon Nitride Films by Reactive Cosputtering. IEEE J. Sel. Top. Quantum Electron., 16(1), 114 (2010).

23. J. M. Ramírez, Rare Earth-Doped Silicon-Based Light Emitting Devices: Towards new Integrated Photonic Building Blocks. Barcelona University; 2015

24. A. L. Tchougréeff and R. Dronskowski, Nephelauxetic effect revisited. Int. J. Quantum. Chem., 109(11), 2606 (2009).

25. J. M. Ramírez, F. Ferrarese Lupi, O. Jambois, Y. Berencén, D. Navarro-Urrios A. Anopchenko et al., Erbium emission in MOS light emitting devices: from energy transfer to direct impact excitation. Nanotechnology, 23(12), 125203 (2012). 